\title{
Pengaruh Embossing Terhadap Kekuatan Lentur dan Kekerasan Pada Sirip Roda Traktor Tangan
}

\author{
Yosrihard B ${ }^{1}$., Muhammad Arsyad Suyuti ${ }^{2 *}$, Syaputra Dermawan ${ }^{3}$, Dewi Ratih $\mathbf{M}^{4}$ \\ 1,2,3,4 Jurusan Teknik Mesin, Politeknik Negeri Ujung Pandang, Makassar 90245, Indonesia \\ 'muhammadarsyadsuyuti@poliupg.ac.id
}

\begin{abstract}
Tractor wheel fins are the most important part of a tractor for plowing a field. The damage to the tractor wheel fins is caused by the lack of ability of the tractor wheel fins to resist bending loads and is affected by the age of the fins themselves. Previous research has made bending tools that can also be used for shaping the hand wheel tractor iron fins with a hydraulic system, with one stage of the bending process, two radius-shaped embossing as reinforcement. Therefore, this study was conducted to find out how the influence of embossing on the flexural strength and hardness of the tractor wheel fins using a variation of the triangle embossing model, number of embossing 1, and embossing height 4, 5, $6 \mathrm{~mm}$ with St 42 carbon steel material, plate thickness $3.8 \mathrm{~mm}$. Based on the results of research carried out the higher the embossing the maximum flexural load produced is greater, where the maximum maximum flexural load obtained by tractor wheel fins with a triangle embossing model, and $6 \mathrm{~mm}$ embossing height obtained flexural stress 147,143 $\mathrm{N} / \mathrm{mm} 2$. The hardness test results of tractor wheel fins with a triangular embossing model, height 6 has the greatest hardness of $171.43 \mathrm{HB}$.
\end{abstract}

Keywords: Wheel tractor fins, Bending stress, High Embossing, Hardness test, Bending test

\begin{abstract}
Abstrak: Sirip roda traktor merupakan bagian terpenting dari sebuah traktor untuk membajak sawah. Rusaknya sirip roda traktor disebabkan karena kurangnya kemampuan sirip roda traktor menahan beban lentur serta dipengaruhi oleh usia sirip itu sendiri. Penelitian sebelumnya telah dibuat alat bantu bending yang juga dapat digunakan untuk pembentuk sirip roda besi traktor tangan dengan sistem hidrolik, dengan satu tahapan proses penekukan, dua embossing berbentuk radius sebagai tulangan. Oleh karena itu, penelitian ini dilakukan untuk mengetahui bagaimana pengaruh embossing pada kekuatan lentur dan kekerasan sirip roda traktor dengan menggunakan variasi model embossing segitiga, jumlah embossing 1, serta tinggi embossing 4, 5, $6 \mathrm{~mm}$ dengan material baja karbon St 42, ketebalan pelat $3.8 \mathrm{~mm}$. Berdasarkan hasil penelitian yang dilakukan semakin tinggi embossing maka beban lentur maksimum yang dihasilkan semakin besar, dimana beban lentur maksimum terbesar diperoleh oleh sirip roda traktor dengan model embossing segitiga, dan tinggi embossing $6 \mathrm{~mm}$ didapatkan tegangan lentur $147,143 \mathrm{~N} / \mathrm{mm}^{2}$. Hasil uji kekerasan sirip roda traktor dengan model embossing segitiga, tinggi 6 memiliki kekerasan terbesar yaitu 171,43 HB.
\end{abstract}

Kata kunci : Sirip roda traktor; Tegangan lentur; Tinggi Embossing, Uji kekerasan, Uji lentur

\section{PENDAHULUAN}

Traktor tangan (hand tractor) merupakan sumber penggerak dari implement (peralatan) pertanian. Biasanya traktor tangan digunakan untuk menarik implement pengolah tanah seperti bajak. Sebagai alat pengolah tanah, traktor tangan memiliki kemampuan adaptasi yang tinggi dengan kondisi lahan di Indonesia. Traktor tangan terdiri dari beberapa komponen penyusun, salah satunya sirip roda besi traktor yang menjadi salah satu komponen fital dari beberapa komponen yang ada. Hal ini dikarenakan sirip roda besi traktor berfungsi sebagai pencecah tanah pada lahan persawahan.

Dalam pembajakan tanah biasanya ditentukan oleh jenis tanaman dan ketebalan lapisan tanah atas. Kedalaman lapisan olah tanah untuk tanaman padi lebih kurang $18 \mathrm{~cm}$ bahkan ada tanah yang harus dibajak lebih dalam lagi sekitar $20 \mathrm{~cm}$ [1]. Salah satu masalah dari penggunaan bajak yaitu apabila di dalam tanah terdapat benda-benda keras maka akan memberikan tahanan yang lebih kuat terhadap sirip roda traktor sehingga dapat membuat sirip roda traktor menjadi melendut. 
Menurut George E. Dieter, biaya kadang-kadang dapat dikurangi dengan menggunakan lembaran logam yang lebih tipis dari normal jika kekuatan dan kekakuan yang meningkat dengan menekuk dan membentuk lembar tulang [2].

Pemeriksaan secara eksperimen dan menggunakan software telah dilakukan dengan berbagai jenis lembaran metal pada proses embossing. Hasil menunjukkan dalam teknik ini digunakan untuk memperbaiki kekakuan dari lembaran pelat. Selanjutnya untuk meningkatkan kekakuan harus mempertimbangkan beberapa parameter seperti jumlah, posisi, tinggi dan jarak dari emboss. Teknik ini juga tidak hanya menekankan meningkatnya kekakuan dari lembaran metal tapi bisa juga untuk membuat lembaran menjadi bentuk yang diinginkan seperti panel, pintu mobil, komponen lainnya [3][4].

Berdasarkan uraian diatas maka, maka permasalahan yang akan diselesaikan dalam penelitian ini yaitu untuk mengetahui pengaruh embossing terhadap kekuatan lentur dan kekerasan sirip roda traktor. Dalam penelitian ini proses pembentukan sirip roda traktor menggunakan alat metal forming yaitu punch dan dies, untuk mengetahui besar gaya yang dibutuhkan untuk membentuk sirip roda traktor dengan satu embossing. Gaya yang dibutuhkan untuk menekuk bagian ujung sirip roda traktor.

$$
\begin{aligned}
& \mathrm{F}_{\mathrm{B} 1}=0,8 \cdot \mathrm{b} \cdot \mathrm{s} \cdot \mathrm{Rm} \\
& \mathrm{F}_{\mathrm{B} 2}=0,5 \cdot \mathrm{b} \cdot \mathrm{s} \cdot \mathrm{Rm}
\end{aligned}
$$

Dimana : $F_{B}=$ Gaya tekuk $(N), b=$ Lebar tekukan $(\mathrm{mm}), \mathrm{s}=$ Tebal pelat $(\mathrm{mm})$ dan $\mathrm{Rm}=$ Tegangan bengkok bahan $\left(\mathrm{N} / \mathrm{mm}^{2}\right)$

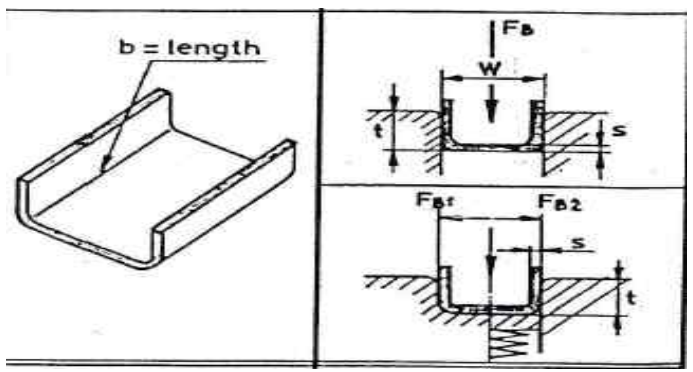

Gambar 1. Gaya pada tekukan 'U-Bending in the die

Dari hasil hitungan besar gaya yang dibutuhkan untuk menekuk bagian ujung sirip roda traktor selanjutnya menghitung besar gaya yang dibutuhkan untuk membentuk emboss.

$$
\mathrm{Fp}=\mathrm{A}_{\text {proj }} . \mathrm{Rm}
$$

Dimana : Fp = Gaya tekuk $(\mathrm{N}), \mathrm{A}_{\text {proj }}=$ Luas Embosing $\left(\mathrm{mm}^{2}\right)$, dan $\mathrm{Rm}=$ Kekuatan tarik bahan $\left(\mathrm{N} / \mathrm{mm}^{2}\right)$.

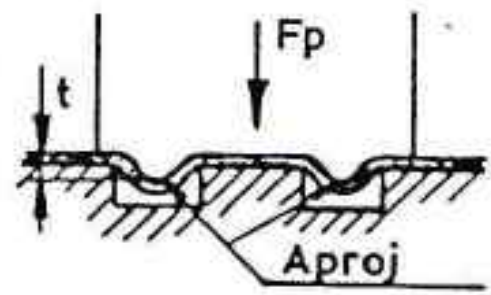

Gambar 2. Pembentukan Embossing

Pengujian lentur adalah pengujian yang dilakukan untuk mengetahui sifat-sifat mekanis serta untuk menentukan mutu suatu material secara visual. Pengujian ini dilakukan untuk mengetahui kekuatan lentur dari sirip roda traktor yang sudah diberikan emboss. Jika semua balok yang ditumpu pada kedua 
ujungnya dan mendapat beban tangensial, maka pada balok tersebut akan mengalami tegangan yang dinamakan tegangan lentur (tegangan bengkok) [5].

$$
\sigma=\frac{M}{W}
$$

Dimana : $\sigma=$ tegangan lentur $\left(\mathrm{N} / \mathrm{mm}^{2}\right), \mathrm{M}=$ momen lentur $(\mathrm{N} \cdot \mathrm{mm})$ dan $\mathrm{W}=$ momen tahanan lentur $\left(\mathrm{mm}^{3}\right)$

Pengujian kekerasan merupakan salah metode yang umum digunakan untuk mengetahui tingkat kekerasan suatu material. Pengujian kekerasan adalah tahanan yang diterima oleh bahan terhadap desakan, disebabkan oleh sebuah alat pendesak dengan bentuk tertentu dibawah gaya tertentu. Pengujian kekerasan dapat dilakukan dengan beberapa metode, antara lain Hard Brinnel (HB), Hard Vickers (HV), HRB (Hard Rockwell Ball) dan HRC (Hard Rockwell Cone). Dari beberapa metode tersebut yang umum digunakan adalah Hard Brinnel (HB).

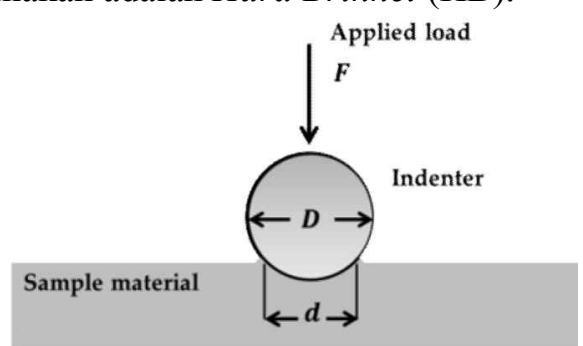

Gambar 3. Prinsip Pengujian Kekerasan Menurut Brinnel

Kekerasan Hard Brinnel (HB) diperoleh dari perbandingan antara gaya $(\mathrm{N})$ dan luas penampang bekas penekanan (A) yang dapat diformulasikan sebagai berikut [5]:

$$
H B=\frac{F}{A} \mathrm{kgf} / \mathrm{mm}^{2}=\frac{9.8 x F}{A} \mathrm{~N} / \mathrm{mm}^{2}
$$

\section{METODE PENELITIAN}

Penelitian ini dilakukan dibengkel Mekanik, Laboratorium CNC dan Laboratorium Mekanik Politeknik Negeri Ujung Pandang. Adapun langkah-langkah proses penelitian yang dilakukan sebagai berikut :

1. Persiapan material. Persiapan material ini bertujuan untuk memastikan bahwa material yang digunakan dalam penelitian yaitu St 42. Sehingga sebelum pembuatan sirip roda traktor maka terlebih dahulu dilakukan pengujian tarik dan kekerasan untuk mengetahui sifat mekanis material tersebut diantaranya: kekuatan tarik dan kekerasan.

2. Pembuatan sampel sirip roda traktor. Pembuatan sampel sirip roda traktor dengan menggunakan mesin potong pelat. Ukuran bahan yang dipersiapkan panjang $340 \mathrm{~mm}$ dan lebar $80 \mathrm{~mm}$ dengan seperti gambar berikut ini:

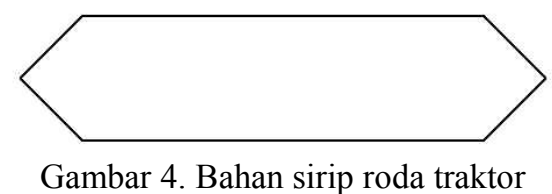

3. Melakukan pembentukan sirip roda traktor tangan menggunakan punch dan dies. Proses pembentukan sirip roda traktor menggunakan punch dan dies yang dipasang pada mesin Press Brake $V$ Bending dengan memvariasikan tinggi embossing yaitu 4, 5, dan $6 \mathrm{~mm}$ model segitiga. 

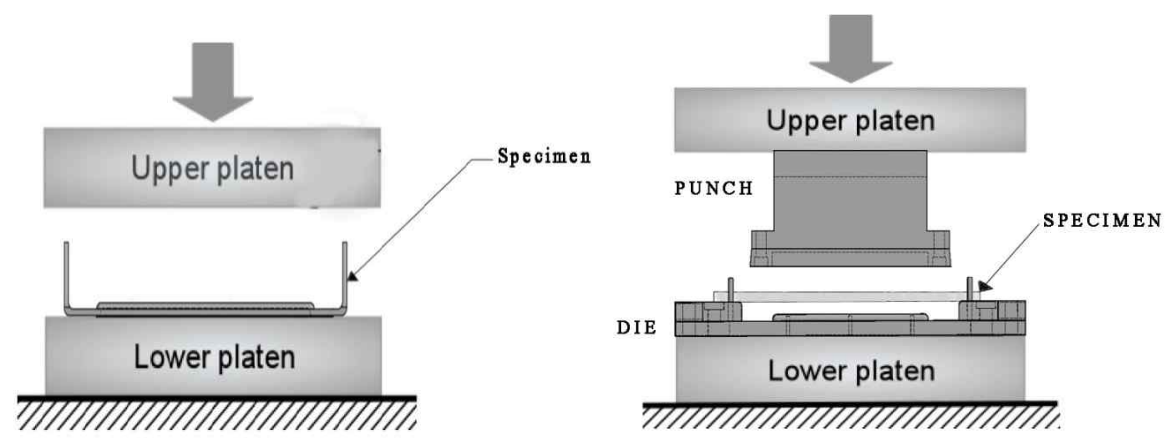

Gambar 5. Metode eksprimen pembentukan emboss pelat lembaran dengan punch dan dies

Hasil dari pembentukan sirip roda traktor tangan menggunakan punch dan dies adalah sebagai berikut :

Tabel 1. Hasil eksperimen

\begin{tabular}{|l|l|}
\hline Parameter & \multicolumn{1}{|c|}{ Satuan } \\
\hline Ukuran spesimen & $270 \mathrm{~mm} \times 80 \mathrm{~mm}$ \\
Tebal pelat & $3,8 \mathrm{~mm}$ \\
Bentuk embossing & Segitiga \\
Lebar embossing & $5 \mathrm{~mm}$ \\
Jumlah embossing & Tanpa dan 1 Embossing \\
Tinggi embossing & $4,5 \mathrm{dan} 6 \mathrm{~mm}$ \\
Panjang embossing & $200 \mathrm{~mm}$ \\
\hline
\end{tabular}

4. Pengujian kekuatan lentur sirip roda traktor. Setelah proses pembentukan sirip roda traktor selesai maka dilanjutkan dengan melakukan pengujian kekuatan lentur menggunakan mesin universal testing machine (UTM) Merek Galdabini PM100 kapasitas 100 KN.

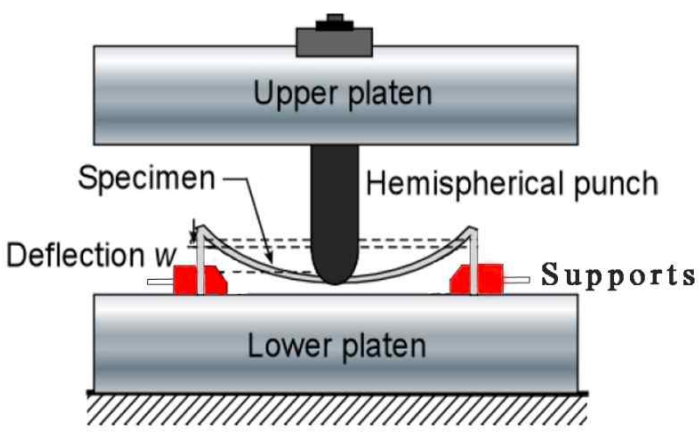

Gambar 6. Metode pengujian lentur

5. Pengujian kekerasan sirip roda traktor menggunakan mesin Affri Hardness Tester dengan metode Brinnel.

\section{HASIL DAN PEMBAHASAN}

\section{A. Hasil Analisis Uji Lentur}

Pengujian lentur dilakukan dengan menggunakan mesin Universal Testing Machine (UTM), dimana sirip roda traktor ditekan sampai gaya maksimum. Pada saat dilakukan pengujian, maka datadata seperti gaya maksimum terdeteksi pada jarum jam pengukuran dan defleksi yang terjadi dapat dilihat pada DTI (Dial Test Indicator). Dalam penelitian ini data dari pengujian lentur yang diamati adalah gaya maksimum, dan defleksi yang terjadi. 
Tabel 2. Hasil pengujian lentur sirip roda traktor satu embossing dan tanpa embossing

\begin{tabular}{|c|c|c|c|c|c|c|c|}
\hline No & $\begin{array}{c}\text { Model } \\
\text { Embossing }\end{array}$ & $\begin{array}{c}\text { Jumlah } \\
\text { Embossing }\end{array}$ & $\begin{array}{c}\text { Tinggi } \\
\text { Embossing } \\
(\mathrm{mm})\end{array}$ & $\begin{array}{c}\mathrm{F} \\
\mathrm{max} \\
(\mathrm{N})\end{array}$ & $\begin{array}{c}\text { Momen } \\
\text { Lentur } \\
(\mathrm{N} . \mathrm{mm})\end{array}$ & $\begin{array}{c}\text { Momen } \\
\text { tahanan lentur } \\
\left(\mathrm{mm}^{3}\right)\end{array}$ & $\begin{array}{c}\text { Tegangan } \\
\text { Lentur } \\
\left(\mathrm{N} / \mathrm{mm}^{2}\right)\end{array}$ \\
\hline 1 & $\Delta$ & 1 & 4 & 2500 & 82000 & 631,5093 & 129,8476 \\
\hline 2 & $\Delta$ & 1 & 5 & 2800 & 91840 & 631,5093 & 145,4294 \\
\hline 3 & $\Delta$ & 1 & 6 & 2833 & 92922,4 & 631,5093 & 147,1434 \\
\hline 4 & $\mathrm{P}$ & - & - & 1766 & 57924,8 & 631,5093 & 91,72438 \\
\hline
\end{tabular}

Berdasarkan hasil pengujian lentur pada Tabel 2 menunjukkan bahwa untuk sirip roda traktor untuk model embossing segitiga dengan tinggi $6 \mathrm{~mm}$ memiliki kekuatan lentur paling besar yaitu 147,143 $\mathrm{N} / \mathrm{mm}^{2}$ jika dibandingkan dengan sirip roda traktor model embossing segitiga tinggi 4, dan $5 \mathrm{~mm}$.

Untuk sirip roda traktor tanpa embossing memiliki kekuatan lentur sebesar $91,724 \mathrm{~N} / \mathrm{mm}^{2}$. Dengan demikian dapat diketahui bahwa sirip roda traktor model embossing segitiga dengan tinggi embossing $6 \mathrm{~mm}$ memiliki kekuatan lentur lebih besar dibandingkan dengan sirip roda traktor yang lain.

\section{B. Hasil Analisis Uji Kekerasan}

Dalam penelitian ini juga dilakukan pengujian kekerasan untuk mengetahui seberapa besar pengaruh embossing terhadap kekerasan sirip roda traktor. Hasil pengujian kekerasan bahan sebelum dibentuk menjadi sirip roda traktor yaitu $121,08 \mathrm{HB}$, lokasi yang diberi beban ada 13 titik pada bagian sirip roda traktor.

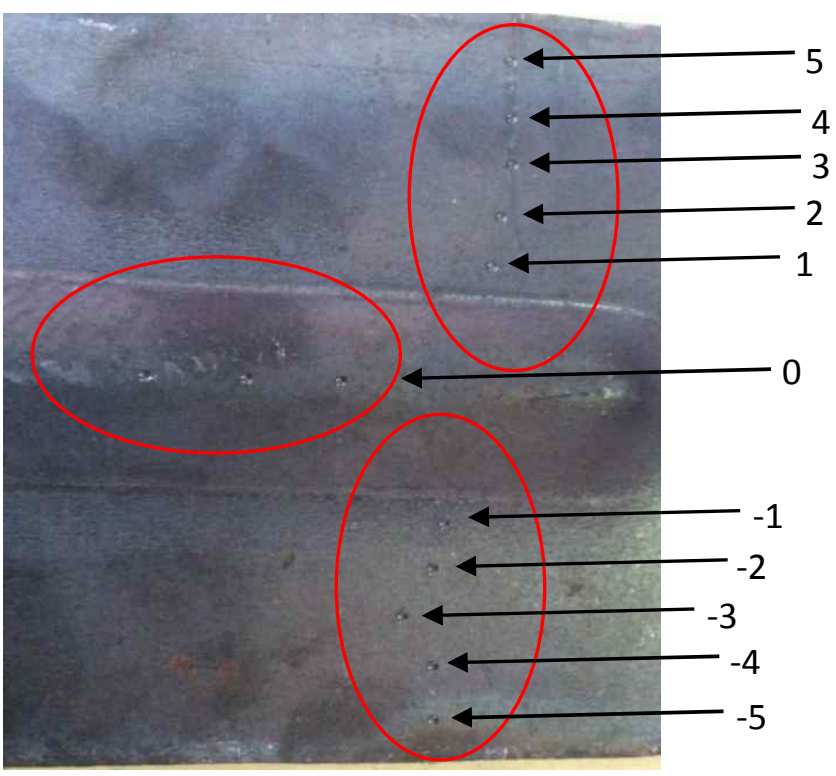

Gambar 7. Lokasi yang diberikan penetrasi

Tabel 3. Hasil uji kekerasan sirip roda traktor dengan embossing model segitiga dengan variasi tinggi

\begin{tabular}{||c|c|c|c|c||}
\hline No & O5 (A) & O5 (B) & O5 (C) & Rerata \\
\hline \hline 5 & 138,8 & 136,8 & 139,2 & 138,267 \\
\hline 4 & 129,6 & 138,8 & 127,2 & 131,867 \\
\hline 3 & 132,5 & 131,4 & 129,2 & 131,033 \\
\hline 2 & 124,8 & 122 & 126,4 & 124,4 \\
\hline 1 & 129,4 & 149,2 & 137,2 & 138,6 \\
\hline
\end{tabular}

\begin{tabular}{||c|c|c|c|c||}
\hline \hline No & O4 (A) & O4 (B) & O4 (C) & Rerata \\
\hline \hline 5 & 132,8 & 138,6 & 128 & 133,133 \\
\hline 4 & 137,6 & 131,2 & 125,6 & 131,467 \\
\hline 3 & 130,2 & 130,8 & 128,2 & 129,733 \\
\hline 2 & 124,8 & 123,8 & 127,2 & 125,267 \\
\hline 1 & 126,6 & 133,5 & 129,6 & 129,9 \\
\hline
\end{tabular}




\begin{tabular}{|c|c|c|c|c||}
\hline 0 & 157,2 & 163,133 & 160,667 & 160,333 \\
\hline-1 & 134,2 & 130,6 & 146,6 & 137,133 \\
\hline-2 & 132 & 130,8 & 128,2 & 130,333 \\
\hline-3 & 125,8 & 132,9 & 123,4 & 127,367 \\
\hline-4 & 134,6 & 139 & 130 & 134,533 \\
\hline-5 & 135 & 140,2 & 140,6 & 138,6 \\
\hline
\end{tabular}

(tinggi embossing $4 \mathrm{~mm}$ )

\begin{tabular}{||c|c|c|c|c||}
\hline 0 & 156,267 & 154,933 & 158,033 & 156,411 \\
\hline-1 & 129,8 & 137,2 & 134,8 & 133,933 \\
\hline-2 & 127,5 & 130,8 & 132,6 & 130,3 \\
\hline-3 & 136,2 & 130,8 & 132,4 & 133,133 \\
\hline-4 & 137,6 & 133,4 & 134,4 & 135,133 \\
\hline-5 & 134 & 130,2 & 136,2 & 133,467 \\
\hline
\end{tabular}

(tinggi embossing $5 \mathrm{~mm}$ )

\begin{tabular}{|c|c|c|c|c||}
\hline No & O6 (A) & O6 (B) & O6 (C) & Rerata \\
\hline \hline 5 & 130,2 & 134 & 128,2 & 130,8 \\
\hline 4 & 122 & 135,4 & 130,8 & 129,4 \\
\hline 3 & 127 & 133,6 & 127,8 & 129,467 \\
\hline 2 & 127,7 & 126,2 & 129,4 & 127,767 \\
\hline 1 & 134,6 & 129,4 & 131,4 & 131,8 \\
\hline 0 & 169,3 & 168,533 & 165,167 & 167,667 \\
\hline-1 & 134,6 & 133,5 & 142,4 & 136,833 \\
\hline-2 & 125,8 & 127,8 & 126,8 & 126,8 \\
\hline-3 & 124,5 & 132,6 & 131,4 & 129,5 \\
\hline-4 & 128,2 & 133,2 & 135,8 & 132,4 \\
\hline-5 & 138,2 & 137,6 & 139 & 138,267 \\
\hline \hline
\end{tabular}

(tinggi embossing $6 \mathrm{~mm}$ )

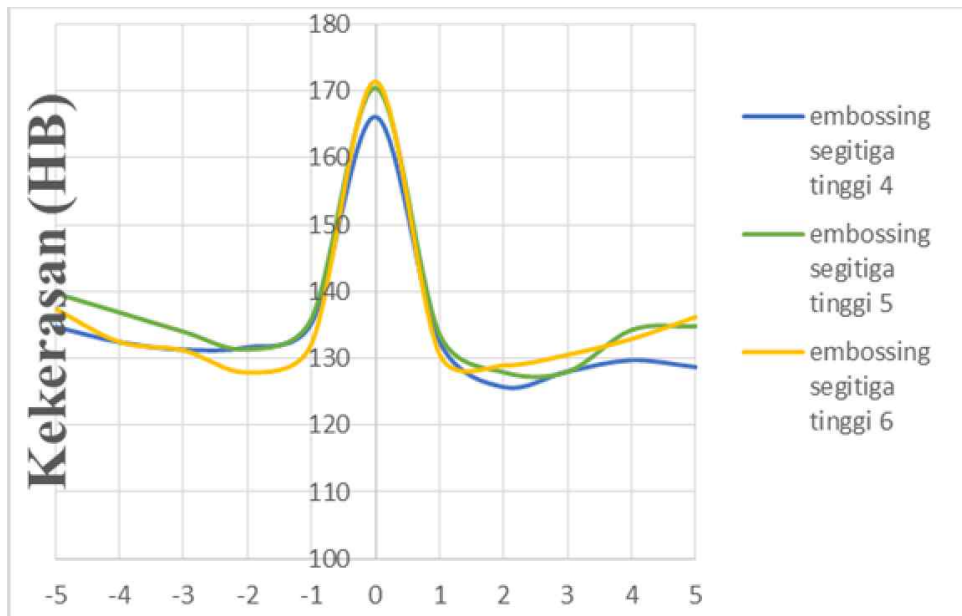

Titik Pembebanan

Gambar 8. Grafik pengujian kekerasan sirip roda traktor model embossing segitiga dengan tinggi 4, 5, dan 6 mm

Berdasarkan hasil uji kekerasan dapat dilihat peningkatan kekerasan yang terjadi sangat signifikan terjadi pada bagian embossing sirip roda traktor. Tinggi embossing mempengaruhi kekerasannya, semakin tinggi embossing maka akan semakin keras pelat tersebut.

Dari hasil uji kekerasan pada tabel 3 dan Gambar 8 dapat dilihat peningkatan kekerasan yang terjadi sangat signifikan terjadi pada bagian embossing sirip roda traktor. Tinggi embossing 
mempengaruhi kekerasannya, semakin tinggi embossing maka akan semakin keras pelat tersebut. Sirip roda traktor model segitiga dengan tinggi embossing $6 \mathrm{~mm}$ memiliki kekerasan pada bagian embossingnya sebesar 171,433 HB. Jika membandingkan kekerasan sirip roda traktor embossing model segitiga dengan tinggi embossing $6 \mathrm{~mm}$ dapat diketahui bahwa memiliki tingkat kekerasan yang lebih besar dibandingkan sirip roda traktor yang lain. Hasil penelitian ini sejalan dengan hasil penelitian yang dilakukan oleh Suyuti dkk yang mempelajari pengaruh springback pada proses Vbending [6].

\section{KESIMPULAN}

Berdasarkan hasil analisis penelitian ini, maka dapat disimpulkan bahwa :

a. Kekuatan lentur sirip roda traktor mengalami peningkatan signifikan dengan diberikan embossing.

b. Kekuatan lentur sirip roda traktor model embossing segitiga dengan tinggi $6 \mathrm{~mm}$ memiliki kekuatan lentur lebih besar yaitu 147,143 N/mm² dibandingkan sirip roda traktor model yang sama dengan tinggi yang berbeda.

c. Kekerasan sirip roda traktor mengalami peningkatan paling signifikan terjadi pada bagian embossingnya dimana kekerasan terbesar terjadi pada sirip roda traktor model embossing segitiga tinggi $6 \mathrm{~mm}$ yaitu 171,433 HB dibandingkan dengan sirip roda traktor yang lain.

\section{DAFTAR PUSTAKA}

[1] E. B. Barbier, "The farm-level economics of soil conservation: the uplands of Java," Land Econ., vol. 66, no. 2, pp. 199-211, 1990.

[2] G. E. Dieter, Reka Bentuk Kejuruteraan. ITBM, 2000.

[3] C. S. Namoco, "Improving the Rigidity of Sheet Metal by Embossing and Restoration Technique," Mindanao J. Sci. Technol., vol. 8, 2010.

[4] C. S. Namoco Jr, T. Iizuka, N. Hatanaka, N. Takakura, and K. Yamaguchi, "Numerical Investigation of Flexural Properties of Sheet Metals Subjected to Embossing and Restoration Process," in Key Engineering Materials, 2007, vol. 340, pp. 377-382.

[5] L. H. Van Vlack and S. Djaprie, Ilmu dan teknologi Bahan. Penerbit Erlangga, 1992.

[6] M. A. Suyuti and R. Nur, "The Influence of Punch Angle on the Spring Back during V-Bending of Medium Carbon Steel," in Advanced Materials Research, 2015, vol. 1125, pp. 157-160. 